\title{
THE SPATIAL DIMENSION OF DRUG PRODUCTION IN ROMANIA
}

\author{
DOI: http://dx.doi.org/10.18509/GBP.2020.79 \\ UDC: 339.3:615.2]:303.71(498)"2000/2018" \\ 338.3:615.2]:303.71(498)"2000/2018"
}

\author{
Cristina Valeria Popescu ${ }^{1,2}$ \\ Andreea Karina Gruia ${ }^{1,2}$ \\ Alexandra Grecu ${ }^{1,2}$ \\ Cătălin Răzvan Dobrea ${ }^{3}$ \\ Arina Mărunțelu ${ }^{1,2}$ \\ ${ }^{1}$ University of Bucharest - Faculty of Geography, Romania \\ ${ }^{2}$ University of Bucharest - Research Center for Integrated \\ Analysis and Territorial Management (CAIMT), Romania \\ ${ }^{3}$ Bucharest University of Economic Studies - Faculty of Management, Romania
}

\begin{abstract}
The global pharmaceutical market is evolving rapidly. The pharmaceutical industry is one of the industries that can significantly contribute to the economic development and creation of added value. This industry, in many countries, has evolved technologically and most pharmaceutical companies are active in the Research-Development field.

The research follows the spatial design of the dynamics of drug production, an economic activity with a spectacular dynamic in recent years. The study was carried out starting from a database that includes the number of employees, turnover, profit and number of companies in this field, for the period 2000-2018. In order to obtain the spatial dynamics, a series of cartographic models were developed for the four indicators, using the opensource QGis platform.

The obtained results highlighted a series of regional specificities determined by the tradition of drug production and particular developments generated by the manifestation of the economic crisis in Romania.
\end{abstract}

Keywords: drug production, pharmaceutical market, economic development

\section{INTRODUCTION}

When we are taking about the pharmaceutical industry, the focus is on two major directions: research and development, known as R\&D and commercial activities where the product is marketed and contributes to the patient access to medicines and treatments. From the moment when a molecule is discovered, it's path is going to be a long one and includes important phases, such as: clinical development (from early development which is phase I trial - molecule tested on a small population to late development which is phase IV trial, when the drug has already been placed on the market), regulatory approval and a close monitoring on the possible adverse reactions. All these steps are part of the R\&D process because it includes, on one hand the drug discovery and on the other hand the clinical development [1].

From a business prospective, the industry is a profitable one, but it is also very risky because before to reach the final molecule that will be the new drug, hundreds of chemical compounds must be synthesized at first and get tested in order to achieve the desirable result. The new drug, before getting the approval requires about 8 years to be studied and tested, so in the first phase of the drug lifecycle, the cash flow is negative due to the 
R\&D's expenses. Patent protections, marketing exclusivity or life cycle innovation are a few examples of strategic steps must to be taken by the pharmaceutical companies in order to be economically viable and continue innovating [2].

The Europe 2020 Strategy, prepared by the European Union for the economic growth is aiming to develop a sustainable and intelligent economy. For this, improving research and innovation, no matter of the field is an important pillar because this will generate jobs, social cohesion and productivity. The research and development intensity, an indicator used in Eurostat reports which represents the specific total expenditures as a percentage of GDP, shows that in European Union the level is about $2.07 \%$ while in US is $2.76 \%$ (in 2015). In 2017, the R\&D intensity indicator for Romania was $0.5 \%$ [3], [4]. If we are having a close look, in America, where the pharmaceutical industry is one of the largest industries, the investment in research and development (R\&D) is about $\$ 75$ billion annually and gives 4.7 million jobs across the country, so the contribution to the economy is a significant one [2].

Regarding the second major direction of pharmaceutical industry, the commercial part, we are talking about the medical affairs, market access, marketing and sales force that contribute to an ethical promotion of the drug [1].

In addition to the contribution to the world economy, the pharmaceutical industry, by ensuring the health status of the population, contributes to the social change and shapes the people's perceptions about what healthcare or illness means [5].

Between the two main pillars, $R \& D$ and commercial part, there is the effective drug production. The manufacturing process of pharmaceutical products consists of designing, planning and scheduling every process phase. The aim is to reduce the costs and improve the good working of the manufacturing systems [6]. And the reason of it is to improve permanently the quality and the patients' satisfaction [7].

World Economic Forum (WEF) Report highlights that manufacturing is significantly important to the prosperity of nations "with over $70 \%$ of the income variations of 128 nations explained by differences in manufactured product export data alone"

McKinsey Global Institute highlights that the manufacturing role in the economy changes over time and it differs according to the economic development stage of any country. This is why, in developed countries manufacturing has the ability to drive productivity growth, innovation and trade [8], [9].

The focus of our investigation is Romania, an Eastern-Center European country. In the National Health Strategy, elaborated by the Ministry of Health for 2014-2020, one of the objectives was to improve the infrastructure of public health services, implicitly of the internal production of medicines and vaccines [10].

\section{METHODOLOGY}

The study aims to analyze the distribution of drug production at the national level on the basis of four economic indicators - number of companies, turnover, number of employees and profit.

The analysis of the dynamics and distribution of drug production at the national level was been made for the time span between 2000 and 2018. For the spatial distribution were chosen as analysis benchmarks the years: 2000 (the beginning of the analysis period), 2008 (the beginning of the economic crisis), 2009 (the year when the effects of the economic crisis are felt) and the last reference year - 2018.

Has been created an economic database at the level of administrative-territorial unit, highlighting 4 economic indicators relevant to the analysis of drug production (number 
of companies, turnover, number of employees and profit) according to the Classification of National Economy Activities (NACE). The NACE codes belonging to the drug production sector are 2110 which represents Manufacture of basic pharmaceutical products and 2120 which represents Manufacture of pharmaceutical preparations (Table 1).

Table 1. NACE codes for the drug production sector

\begin{tabular}{ccc}
\hline $\begin{array}{c}\text { NACE } \\
\text { codes }\end{array}$ & Pharmaceutical activities & $\begin{array}{c}\text { Field of activity according to } \\
\text { NACE }\end{array}$ \\
\hline 2110 & $\begin{array}{c}\text { Manufacture of basic pharmaceutical } \\
\text { products }\end{array}$ & \\
2120 & $\begin{array}{c}\text { Manufacture of pharmaceutical } \\
\text { preparations }\end{array}$ & MANUFACTURING \\
\hline & 0
\end{tabular}

Using the QGIS 3.4 open-source software, maps were created for the four years considered relevant to the study (2000, 2008, 2009 and 2018), for the 4 indicators, in a sequential color scheme, using centroid type filling with simple symbol, and the symbol size increases as the number of elements in a territorial administrative unit increases (number of companies, number of employees, turnover and profit value).

The graphical models show the evolution of the indicators, with the highlights of the maximum value for each indicator.

The values for turnover, for a better analysis, are expressed in the national currency (Lei), thus that at the course of the National Bank of Romania 1 euro represents 4.75 Lei.

\section{RESULTS}

\section{Number of companies}

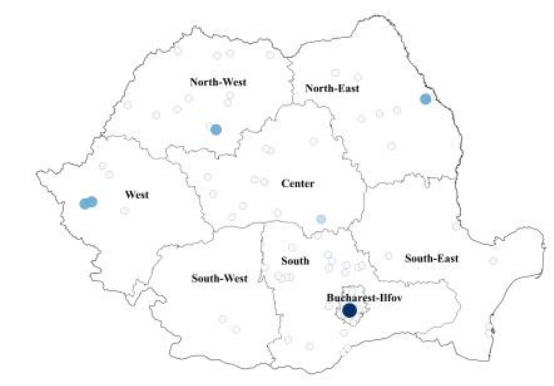

2000

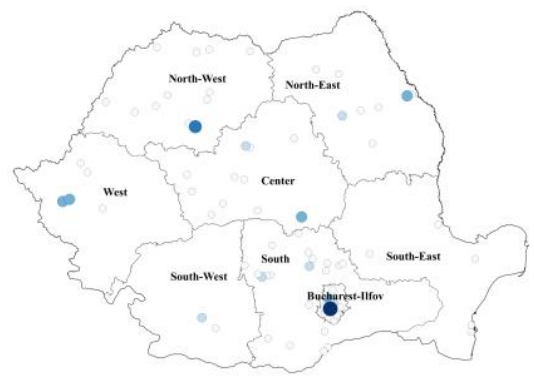

2009

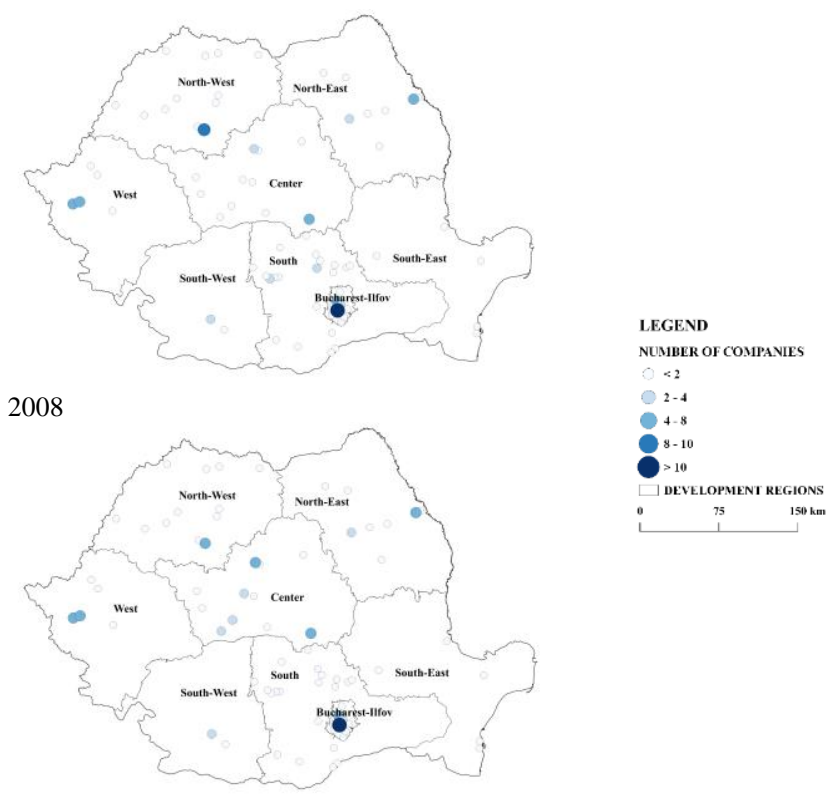

2018

Figure 1. Spatial distribution of companies in the Romanian drug production sector Source: UB/1423

In 2000, the most 3 important cities regarding the pharmaceutical production units were Bucharest with 28 companies, followed by Cluj and Iași with 6 companies. In 2008, Bucharest remains the leader with 54 companies, on the second place is Cluj with 10 
companies, followed by Iași with 7 companies. The year 2009 ensures the three cities almost the same units, Bucharest having a decrease of 3 production companies, Cluj and Iași remaining the same with 10 companies and 7 companies. Nine years later, in 2018, we can see a decrease in the production units in Bucharest, 59 units, in Timișoara, the second city we reached 8 production companies, while Iasi remains with the same 7 production companies.

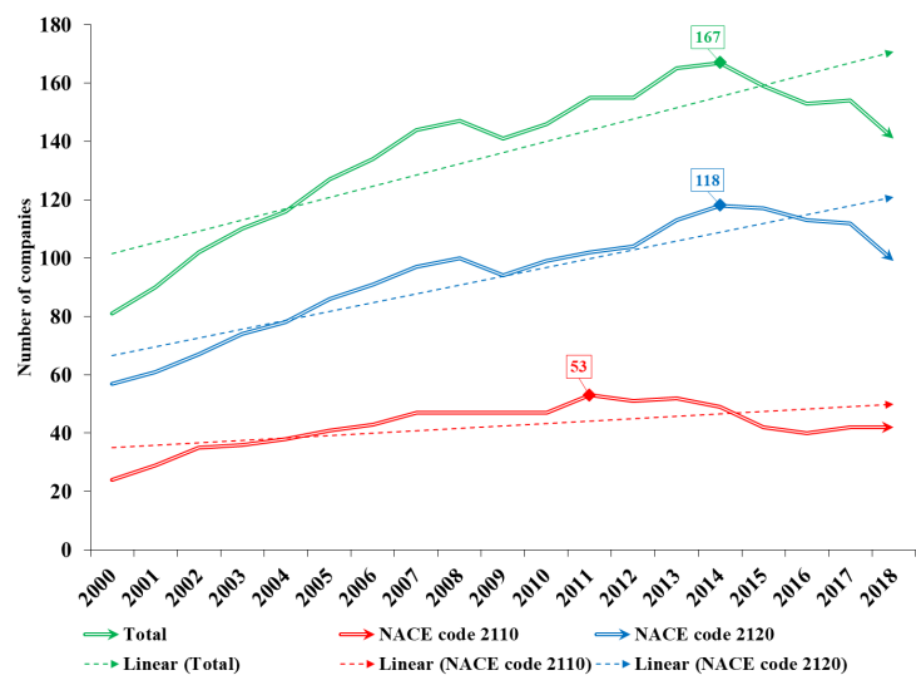

Figure 2. Evolution of the companies in the Romanian drug production sector for the period 2000-2018 Source: UB/1423

The evolution of the total number of companies in the drug production sector shows a downward trend, with a maximum value of 167 companies in 2014 out of this total of 49 companies belonging to NACE code 2110 - Manufacture of basic pharmaceutical products and 118 companies to NACE code 2120 - Manufacture of pharmaceutical code preparations, which show descending evolutions reaching in 2018 to 42 companies for 2110 and 99 companies for 2120 .

\section{Turnover}

The turnover of the pharmaceutical production units in 2000 registered Bucharest the first city of the country with 144 mil. lei turnover, followed by Iași with 64.7 mil. lei and Brașov with 54.8 mil. lei. In 2008, Bucharest leads the cities with 520.5 mil. lei, followed by Mureș with 352 mil. lei and Cluj with 312.7 mil. lei. For the next year, 2009, Bucharest registered a turnover of 616.4 mil. lei, followed by Brașov 431.8 with and Mureș with 364.2 mil. lei. In 2018, on the other hand, the Bucharest pharmaceutical production units reached 1.2 bil. lei, followed by Cluj with 744.3 mil. lei and Mureș with 525.9 mil. lei. The evolution of the total turnover in the drug production sector shows a fluctuating trend, with a maximum value - 3,809,138,831 lei companies in 2015 out of this total of 993,708,634 lei belonging to NACE code 2110 - Manufacture of basic pharmaceutical products and 2,815,430,197 to NACE code 2120 - Manufacture of pharmaceutical code preparations, which show fluctuating evolutions, reaching in 2018 a total turnover that summing a number of 3770349710 lei and 1,096,371,538 lei for 2110 and 2,673,978,172 for 2120 . 


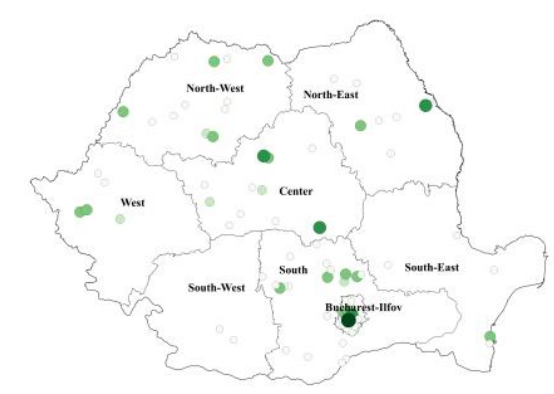

2000

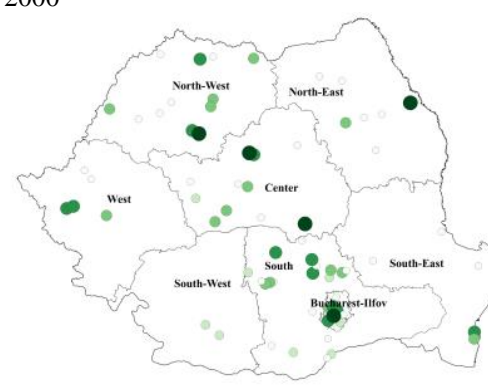

2009

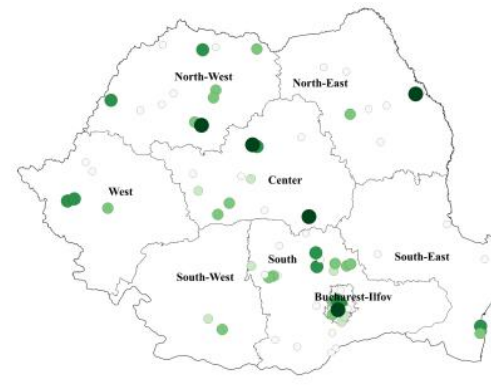

2008

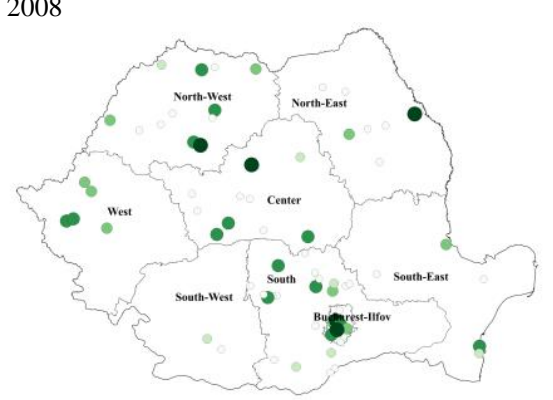

2018

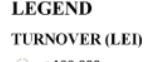

$<100.000$

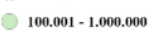

$1.000 .001-10.000 .000$ $10.000 .001-100.000 .000$ $>100.000 .001$ $\checkmark$ DEVELOPMENT REGIONS $75 \quad 150 \mathrm{~km}$

Figure 3. Spatial distribution of turnover in the drug production sector in Romania Source: UB/1423

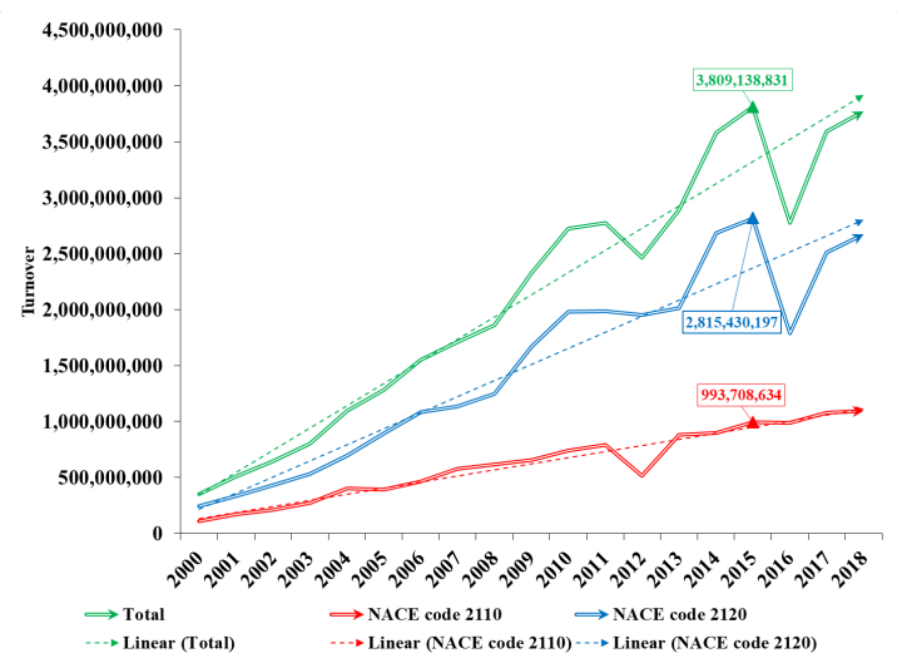

Figure 4. Evolution of the turnover (Lei) in the drug production sector in Romania for the period 2000-2018 Source: UB/1423

\section{Number of employees}

Regarding the number of employees, in 2000, the most important cities were Bucharest with 3862 employees, Iași with 2006 employees and Brașov with 726 employees. In 2008, the number of employees decreased in Bucharest, reaching 2828, followed by Iași with 1725 and Cluj with 992 employees. After one year of crisis, in 2009, the number of employees in Bucharest increase with 4\%, reaching 2938 employees. On the other hand, we can find a decrease in Iași with 6\%, reaching 1613 employees and in Cluj with $10 \%$, reaching 889 employees. In 2018, in Bucharest, the number of employees decrease too, reaching 2500 employees in the pharmaceutical production field, followed by Iasi with 1665 employees and Mureș with 908 employees. 


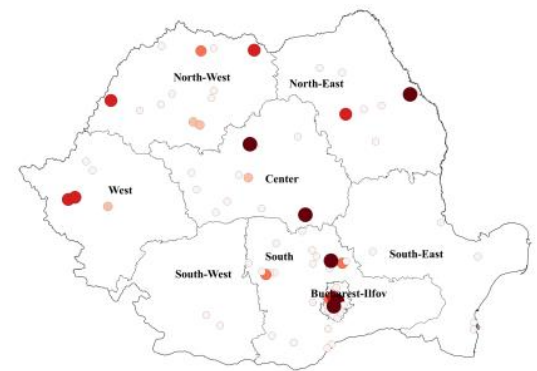

2000

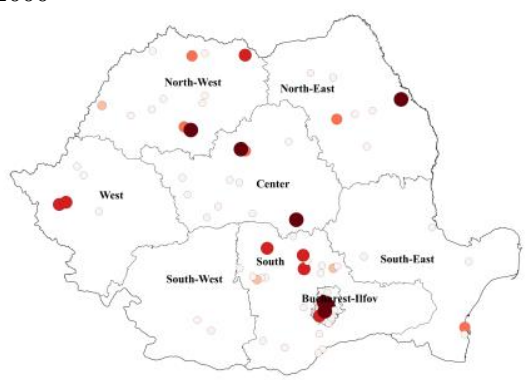

2009

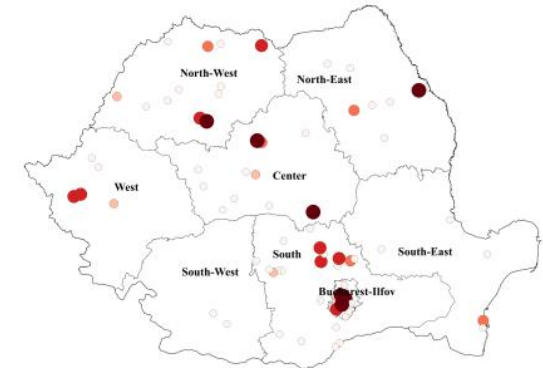

2008

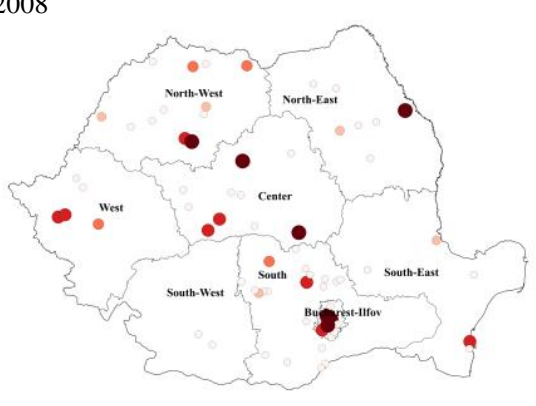

2018
LEGEND

NUMBER OF EMPLOYEES

$<25$

25- 60

$60-100$
$100-250$

$>250$

DEVELOPMENT REGIONS

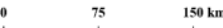

Figure 5. Spatial distribution of the number of employees in the drug production sector in Romania Source: UB/1423

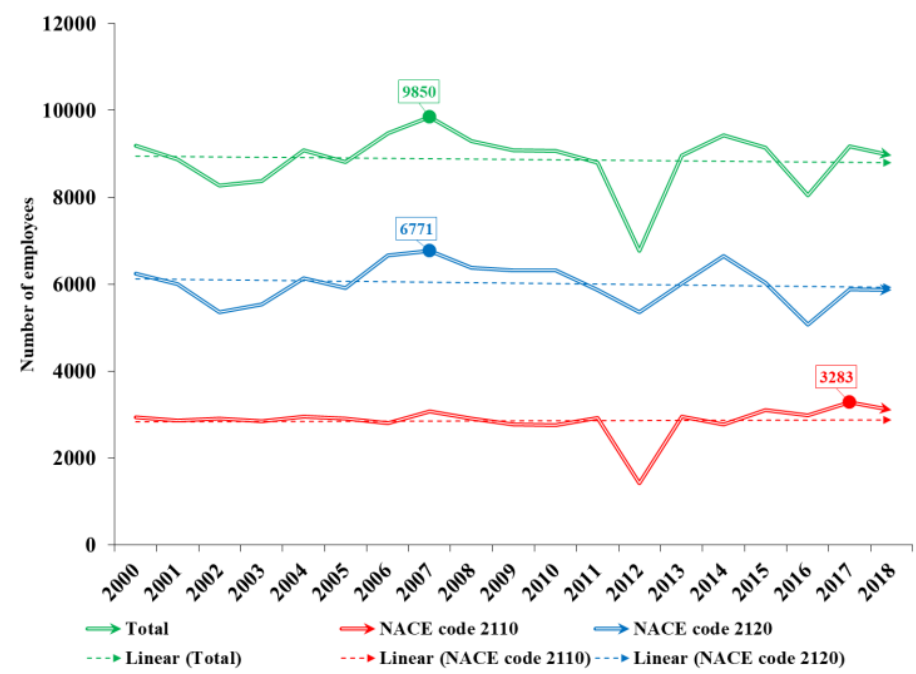

Figure 6. Evolution of the number of employees in the drug production sector in Romania for the period 2000-2018 Source: UB/1423

The evolution of the total number of employees in the drug production sector shows a downward trend, with a maximum value of 9750 employees in 2007 out of this total of 3079 employees belonging to NACE code 2110 - Manufacture of basic pharmaceutical products and 6771 employees to NACE code 2120 - Manufacture of pharmaceutical code preparations, which show fluctuating evolutions and a decrease for year 2012, evolutions that get in 2018 a total number of 8967 employees and from that number 3098 employees belonging to NACE code 2110 and 5869 employees for NACE code 2120. 


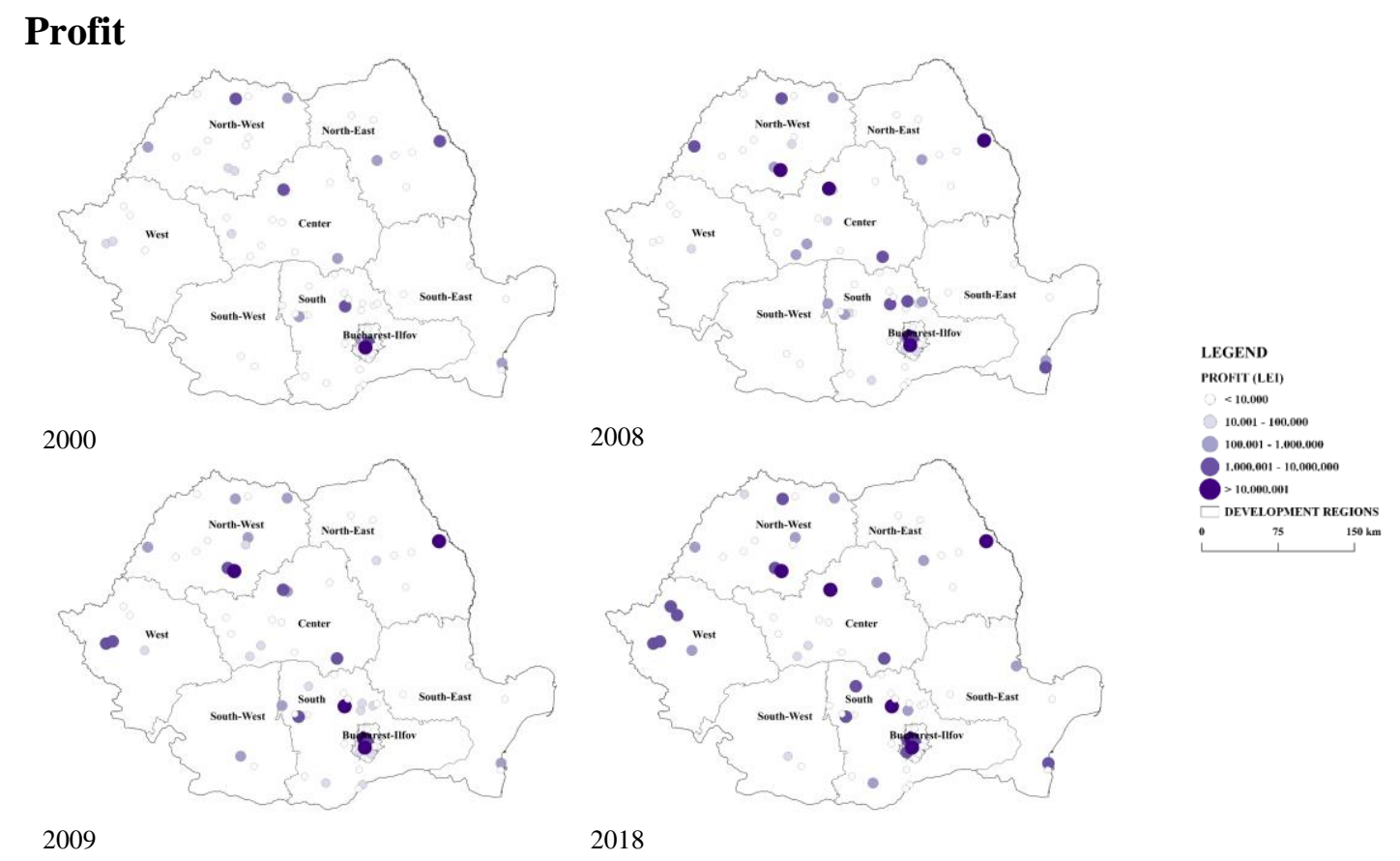

Figure 7. Spatial distribution of profit in the drug production sector in Romania Source: UB/1423

In 2000, the most three profitable cities in the pharmaceutical commerce were Bucharest with 25.4 mil. lei, Iasi with 4.8 mil. lei and Prahova with almost 3.1 mil. lei profit. In 2008, the first city remains Bucharest with 38.9 mil. lei, followed by Cluj with 32.8 mil. lei and Ilfov with 16.2 mil. lei profit from the pharmaceutical production field. 2009 , the year after the crisis, the profit for the first city, Bucharest, was 50 mil. lei, for the second which was Cluj was 40.3 mil. lei and for the third city, Ilfov, was 22.2 mil. lei. Nine years later, in 2018, Bucharest pharmaceutical production units registered a profit of 400.4 mil. lei. The second most profitable city was Cluj with a $149.1 \mathrm{mil}$. lei, followed by Ilfov with 87 mil. lei.

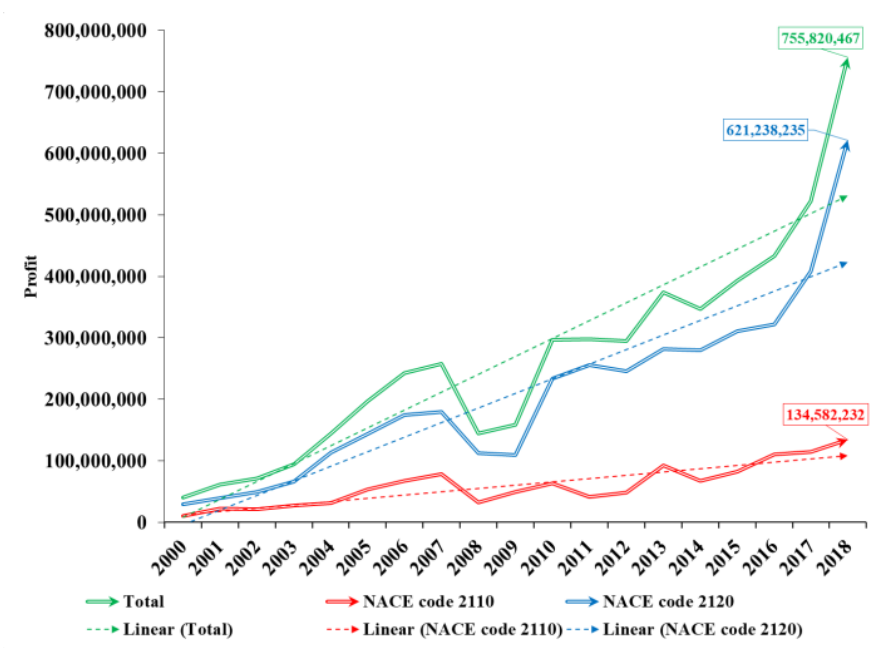

Figure 8. Evolution of profit (Lei) from the Romanian drug production sector for the period 2000-2018 Source: UB/1423

The evolution of the total profit in the drug production sector shows a fluctuating trend, with a maximum value - 7,558,204,67 lei in 2018 out of this total of 134,582,232 lei 
belonging to NACE code 2110 - Manufacture of basic pharmaceutical products and $621,238,235$ to NACE code 2120 - Manufacture of pharmaceutical code preparations. It is presenting a fluctuating trend for the three evolutions analyzed, with decreases in years that follow the economic crisis and with increases after 2010.

\section{CONCLUSIONS}

The analysis of the spatial dimension of drug production has revealed many specificities, the most important being the small increase in the number of territorial administrative units that have production units. The well-known centers are maintained throughout the analyzed period.

Although there were no new production centers, the production of medicines became one of the most profitable in Romania, with a relatively constant number of employees being obtained a number of jobs with spectacular growths. Also, the profit has jumped very high compared to any other production sector.

The analysis of the impact of drug production on local and regional development requires a broader analysis, based on algorithms that capture the effects of these specific dynamics on the other components of the local economy. In this sense, fractal algorithms can be used which have resulted in other areas such as the impact of deforestation on local economies and the role of creative economies in the development of local economies [11], [12], [13], [14], [15], [16], [17].

\section{REFERENCES}

[1] Sweiti H., Wiegand F. et al. Physicians in the pharmaceutical industry: their roles, motivations and perspectives, Drug discovery today, vol. 23, pp 1865-1869, 2019.

[2] Mittal B. Pharmaceuticals: a highly innovative business, How to Integrate Quality by Efficient Design (QbED) in Product Development, Expertise in Pharmaceutical Process Technology, USA, pp 27-57, 2020.

[3] Iancu V. Romania in the context of European innovation and marketing of intellectual output, Procedia Economics and Finance, vol. 8, pp 380-387, 2014.

[4] Eurostat Press Office, Eurostat News release. First estimates of Research \& Development expenditure R\&D expenditure in the EU increased slightly to 2.07\% of GDP in 2017, pp 1-2.

[5] Sismondo S. Pharmaceutical Industry: Political Economies of Drugs and Knowledge, International Encyclopedia of the Social \& Behavioral Sciences (Second Edition), Canada, pp 610, 2015.

[6] Moniz S., Barbosa-Póvoa A., Pinho de Sousa J. On the complexity of production planning and scheduling in the pharmaceutical industry: The Delivery Trade-offs Matrix, Portugal, 2015.

[7] Karam A., Liviu M. et al. The contribution of lean manufacturing tools to change overtime decrease in the pharmaceutical industry. A SMED project, Procedia Manufacturing, vol. 20, pp 886-892, 2014.

[8] World Economic Forum, The Future of Manufacturing Opportunities to drive economic growth, pp. 59, 2012.

[9] Herman E. The Importance of the Manufacturing Sector in the Romanian Economy, Procedia Technology, vol. 22, pp 976-983, 2016.

[10] National Health Strategy 2014-2020 for Romania, pp 73, 2014.

[11] Andronache I., Marin M., Fischer R., Ahammer H., Radulovic M., Ciobotaru A. M., Jelinek H. F., Di Ieva A., Pintilii R. D., Drăghici C.C., Herman G. V., Nicula A. S., Simion A. G., Loghin I. V., Diaconu D.C., Peptenatu D., Spatial-Temporal Dynamics of Forest Fragmentation and 
Connectivity Using Particle and Fractal Analysis, Scientific Reports, 2019. DOI: https://doi.org/10.1038/s41598-019-48277-z

[12] Diaconu D.C., Andronache I., Pintilii R.D., Bretcan P., Simion A.G., Draghici C.C., Gruia K.A., Grecu A., Marin M., Peptenatu D., Using fractal fragmentation and compaction index in analysis of the deforestation process in Bucegi Mountains group, Romania, Carpathian Journal of Earth and Environmental Sciences, 2019. DOI: http://doi.org/10.26471/CJEES/2019/014/092

[13] Gruia A.K., Dobrea R.C., Simion C.P., Dima C., Grecu A., Hudea O.S., Marin M., Andronache I., Peptenatu D., The Use of Sholl and Kolmogorov Complexity Analysis in Researching on the Sustainable Development of Creative Economies in the Development Region of Bucharest-Ilfov, Romania, Sustainability, vol. 11, 6195, 2019. DOI: doi:10.3390/su11226195

[14] Ciobotaru A.M., Andronache I., Ahammer H., Jelinek H.F., Radulovic M., Pintilii R.D., Peptenatu D., Drăghici C.C., Simion A.G., Papuc R.M., Marin M., Radu R.A., Grecu A., Gruia A.K., Loghin I. V., Fensholt R., Recent Deforestation Pattern Changes (2000-2017) in the Central Carpathians: A Gray-Level Co-Occurrence Matrix and Fractal Analysis Approach, Forests,10, 308, 2019. DOI:10.3390/f10040308

[15] Grecu A., Gruia A.K., Marin M., Bănuță M., Olteanu C., Constantin I., Gadoiu M., Teodorescu C., Dobrea R.C., Drăghici C.C., Specificity of Sustainable Structural Dynamics of Local Economy in Romanian Tourist Resorts, Sustainability, vol. 11, 7155, 2019. DOI: doi:10.3390/su11247155

[16] Manea G., Matei E., Vijulie I., Marin M., Cocoș O., Tișcovschi A., Tradition and modernity in the romanian rural space. case study: the Arges sub-carpathian foothills, Eastern European Countryside Journal (EEC, 19-2013) ISSN 1232-8855, 2013.

[17] Pintilii R.D., Peptenatu D., Draghici C., Irina S., Stoian R.D., Structural Changes in The Entrepreneurial Profile of The Creative Industries in Romania, 2nd Global Conference on Business, Economics, Management and Tourism, Edited by: Iacob, A.I., Procedia Economics and Finance, vol. 23, pp: 1147-1151, 2015. 